\title{
Article
}

\section{Low Tumor-to-Stroma Ratio Reflects Protective Role of Stroma against Prostate Cancer Progression}

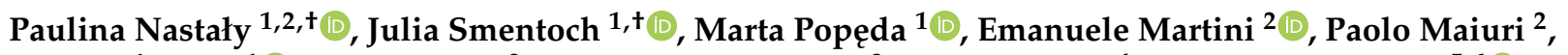 \\ Anna J. Żaczek ${ }^{1}{ }^{(}$, , Marek Sowa $^{3}$, Marcin Matuszewski ${ }^{3}$, Jolanta Szade ${ }^{4}$, Leszek Kalinowski ${ }^{5,6} \mathbb{D}_{\text {, }}$ \\ Magdalena Niemira ${ }^{7}\left(\mathbb{D}\right.$, Burkhard Brandt ${ }^{8}\left(\mathbb{D}\right.$, Elke Eltze ${ }^{9}$, Axel Semjonow ${ }^{10}$ and Natalia Bednarz-Knoll $1, *(\mathbb{C}$
}

1 Laboratory of Translational Oncology, Medical University of Gdańsk, 80-210 Gdańsk, Poland; paulina.nastaly@gumed.edu.pl (P.N.); julia.smentoch@gumed.edu.pl (J.S.); marta.popeda@gmail.com (M.P.); azaczek@gumed.edu.pl (A.J.Ż.)

2 FIRC (Italian Foundation for Cancer Research), Institute of Molecular Oncology (IFOM), 20139 Milan, Italy; emanuele.martini@ifom.eu (E.M.); paolo.maiuri@ifom.eu (P.M.)

3 Department of Urology, Medical University of Gdańsk, 80-214 Gdańsk, Poland; mareczek.so@gumed.edu.pl (M.S.); marcin.matuszewski@gumed.edu.pl (M.M.)

4 Department of Pathomorphology, Medical University of Gdańsk, 80-214 Gdańsk, Poland; jszade@gumed.edu.pl

5 Department of Medical Laboratory Diagnostics-Biobank, Medical University of Gdańsk, 80-210 Gdańsk, Poland; leszek.kalinowski@gumed.edu.pl

6 Biobanking and Biomolecular Resources Research Infrastructure (BBMRI.pl), 80-214 Gdańsk, Poland

7 Clinical Research Centre, Medical University of Bialystok, 15-276 Bialystok, Poland; magdalena.niemira@umb.edu.pl

check for

updates

Citation: Nastały, P.; Smentoch, J.; Popęda, M.; Martini, E.; Maiuri, P.; Żaczek, A.J.; Sowa, M.; Matuszewski, M.; Szade, J.; Kalinowski, L.; et al. Low Tumor-to-Stroma Ratio Reflects Protective Role of Stroma against Prostate Cancer Progression. J. Pers. Med. 2021, 11, 1088. https://doi.org/ $10.3390 /$ jpm11111088

Academic Editor: Wojciech Krajewski

Received: 10 September 2021

Accepted: 23 October 2021

Published: 26 October 2021

Publisher's Note: MDPI stays neutral with regard to jurisdictional claims in published maps and institutional affiliations.

Copyright: (c) 2021 by the authors. Licensee MDPI, Basel, Switzerland. This article is an open access article distributed under the terms and conditions of the Creative Commons Attribution (CC BY) license (https:// creativecommons.org/licenses/by/ $4.0 /)$.
8 Institute of Clinical Chemistry, University Medical Centre Schleswig-Holstein, 24105 Kiel, Germany; burkhard.brandt@uksh.de

9 Institute of Pathology Saarbruecken-Rastpfuhl, 66113 Saarbruecken, Germany; e.eltze@pathologie-saarbruecken.de

10 Department of Urology, Prostate Center, University Clinic Münster, 48149 Münster, Germany; axel.semjonow@ukmuenster.de

* Correspondence: nbk@gumed.edu.pl; Tel.: +48-58-349-14-34

+ Equal contribution.

Abstract: Tumor-to-stroma ratio (TSR) is a prognostic factor that expresses the relative amounts of tumor and intratumoral stroma. In this study, its clinical and molecular relevance was evaluated in prostate cancer $(\mathrm{PCa})$. The feasibility of automated quantification was tested in digital scans of tissue microarrays containing 128 primary tumors from 72 PCa patients stained immunohistochemically for epithelial cell adhesion molecule (EpCAM), followed by validation in a cohort of 310 primary tumors from 209 PCa patients. In order to investigate the gene expression differences between tumors with low and high TSR, we applied multigene expression analysis (nCounter ${ }^{\circledR}$ PanCancer Progression Panel, NanoString) of 42 tissue samples. TSR scores were categorized into low ( $<1$ TSR) and high ( $\geq 1$ TSR). In the pilot cohort, 31 patients $(43.1 \%)$ were categorized as low and $41(56.9 \%)$ as high TSR score, whereas $48(23.0 \%)$ patients from the validation cohort were classified as low TSR and $161(77.0 \%)$ as high. In both cohorts, high TSR appeared to indicate the shorter time to biochemical recurrence in PCa patients (Log-rank test, $p=0.04$ and $p=0.01$ for the pilot and validation cohort, respectively). Additionally, in the multivariate analysis of the validation cohort, TSR predicted BR independent of other factors, i.e., $\mathrm{pT}, \mathrm{pN}$, and age ( $p=0.04, \mathrm{HR} 2.75,95 \% \mathrm{CI} 1.07-7.03)$. Our data revealed that tumors categorized into low and high TSR score show differential expression of various genes; the genes upregulated in tumors with low TSR score were mostly associated with extracellular matrix and cell adhesion regulation. Taken together, this study shows that high stroma content can play a protective role in PCa. Automatic EpCAM-based quantification of TSR might improve prognostication in personalized medicine for PCa.

Keywords: prostate cancer; tumor-to-stroma ratio; biochemical recurrence; tumor progression; digital pathology 


\section{Introduction}

Prostate cancer ( $\mathrm{PCa})$ is the second of the most frequently diagnosed cancers among men worldwide [1,2]. Although the prostate-specific antigen (PSA) blood test is a widely used screening tool allowing for earlier diagnosis, it possesses some limitations in identifying patients with significant PCa or at the high risk of progression [3]. Therefore, there is a need for other prognostic marker(s) refining risk stratification and/or supporting treatment decisions.

Tumoral stroma is recognized as one of the key players [4,5] during cancer development, progression [6], or even therapy resistance [7]. Its main role includes the formation of structure and/or remodeling of the tissue [7]. In early disease stages, intratumoral stroma may even inhibit tumor progression [7], whereas, later, it frequently influences new vessel formation, inflammation, and, in turn, promotes cancer progression [8].

The intratumoral content of the stroma alone or transformed into the so-called tumorto-stroma ratio (TSR) was reported to be of clinical significance in multiple studies. Indeed, in different solid tumors, both low and high TSR are shown to be associated with the higher risk of cancer progression and poor patients' prognosis $[9,10]$. Low TSR [11-13] occurs as an independent prognostic factor [14], and is associated with more aggressive features of cancer cells in diverse solid malignancies including colon [15-17], rectal [14], gastric [10], non-small cell lung [18], ovarian [19], cervical [20], and breast cancer [21-23]. On the contrary, low stroma content equivalent to high TSR refers to poor prognosis in endometrial and estrogen receptor-positive breast cancer [24,25]. Although TSR has not been described yet in PCa, the clinical significance of both no/little or a high amount of stroma content (i.e., an equivalent of TSR) was shown to be associated with worse recurrence free-survival in this type of cancer [25-27].

Despite its clinical potential, there has not yet been implementation of TSR scoring in routine pathology. It could be due to the variety in methodology and the lack of a standardized procedure for its evaluation. TSR is one of the markers that may suffer from reproducibility issues when assessed visually due to intra- and inter-observer variability. Digitalization and automation of the TSR evaluation process might reduce this variance and facilitate standardization of TSR assessment. Indeed, due to its numerous advantages, digital pathology is rapidly evolving and gaining interest. It allows for faster, more precise, and cost-effective work, reducing the variability between pathologists' evaluation [28-30]. According to the literature data, so far, the automated digital analysis of TSR has been attempted to be performed on digital images [31], using computer-aided quantification [14] or deep learning systems [32].

In $\mathrm{PCa}$, the stroma content has been reported to be automatically quantified from standard hematoxylin-eosin digital scans [26,33]. Epithelial cell adhesion molecule (EpCAM) is widely expressed in PCa [34-36], and can differentiate between tumor and stroma cells. Thus, in the current study, TSR was assessed automatically in digitalized EpCAM-stained tumors and correlated with the clinical outcome and molecular phenotype of tumor cells in PCa patients. Additionally, using multigene expression analysis, the tumors with low and high TSR were compared at the RNA level.

\section{Results}

\subsection{TSR Evaluation in the Pilot and Validation Cohort}

The automated method recognized TSR correctly in tumors with weak $(17.80 \%)$ and moderate to strong (82.20\%) EpCAM expression (Supplementary Figure S1). All tumor samples from the pilot and validation study were assessed automatically followed by visual verification.

Pilot cohort. A total of 128 tumor samples corresponding to $72 \mathrm{~d}$ 'Amico high risk PCa patients fulfilled the technical quality and TSR assessment criteria (Figure 1A). All informative tumor samples were positive for EpCAM staining. In total, the range of TSR values detected in the informative tumor samples was 0.03 to 61.44 , with the median and mean equal to 1.06 and 2.89 , respectively. For each patient, the maximal value obtained 
from eligible tumor samples categorized as low TSR score was $<1(n=31,43.10 \%$ of all patients) or $\geq 1(n=41,56.90 \%)$, respectively (Figure 2$)$.

Pilot cohort

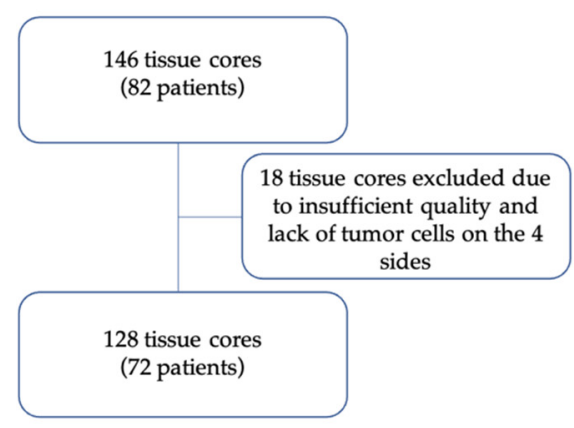

(a)
Validation cohort

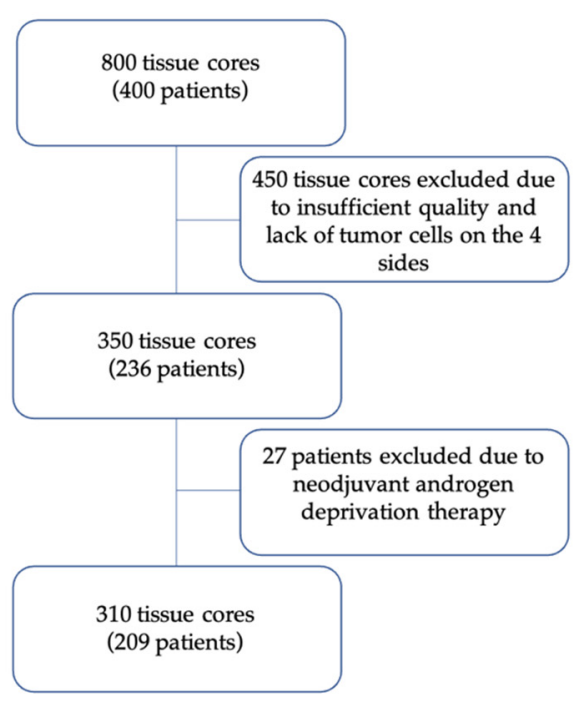

(b)

Figure 1. Schematic diagram of patients' enrollment and exclusion. (a) Patients from the pilot. (b) Patients from and validation cohort.

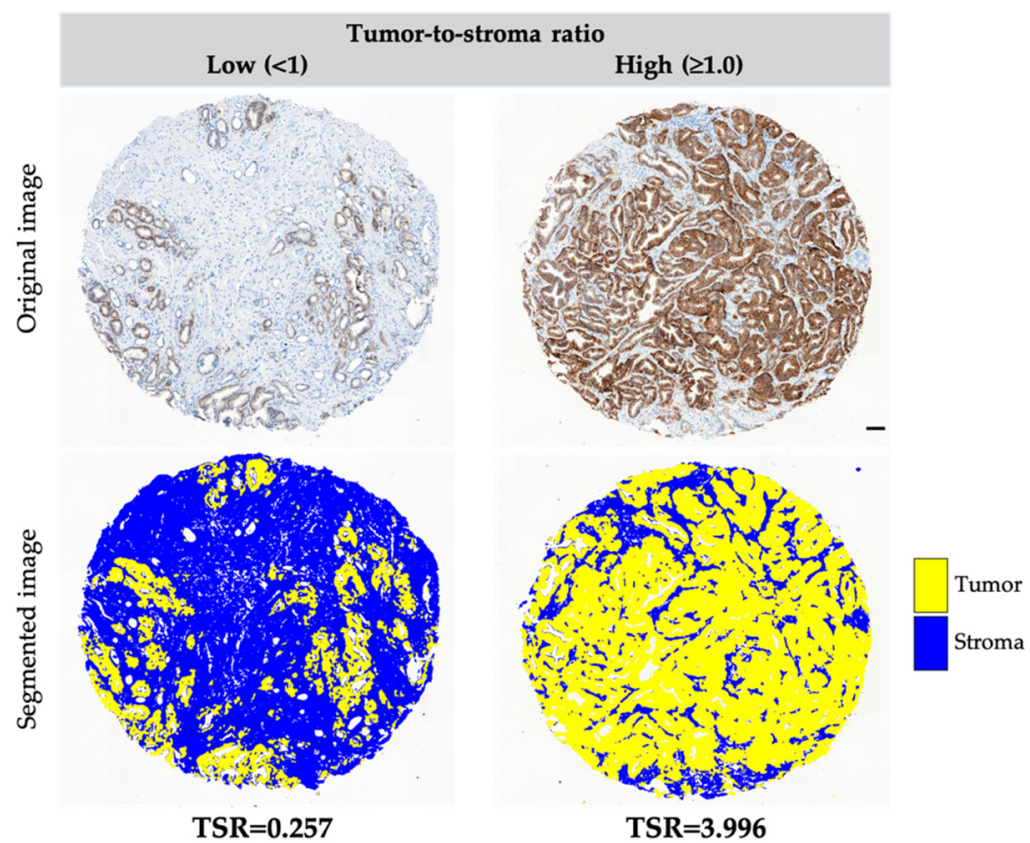

Figure 2. Representative photomicrographs of different TSR categories in prostate carcinomas: low and high. Tumor cells are stained with anti-EpCAM antibody and visualized in brown, whereas stroma is blue. Magnification $100 \times$, scale bar corresponds to $100 \mu \mathrm{m}$.

Validation cohort. A total of 310 tumor fragments corresponding to 209 patients fulfilled the technical quality and TSR assessment criteria, including appropriate tissue quality, presence of tumor cells visible in four sides of the specimens [17], and informative EpCAM staining. These samples were included for the further analysis (Figure 1B). In total, the range of TSR values detected in the informative tumor samples was 0.16 to 27.50 , with the 
median and mean determined as 2.14 and 3.52, respectively. For each patient, the maximal value obtained from eligible tumor samples was categorized as low or high TSR if TSR score was $<1$ ( $n=48,23.00 \%$ of all patients) or $\geq 1(n=161,77.00 \%)$, respectively (Figure 2 ).

\subsection{Clinical Significance of TSR in the Pilot Cohort}

When compared to the available clinico-pathological parameters, TSR score did not correlate to patient's age, pT status, $\mathrm{pN}$ status, and preoperative PSA in the pilot cohort (Supplementary Table S1). TSR correlated to higher Gleason Grading score (Fisher's exact test, $p=0.03)$. In the survival analysis, high TSR appeared to indicate a shorter time to biochemical recurrence in the pilot cohort of PCa patients (Log-rank test, $n=72, p=0.0373$, Figure 3$)$. In uni- and multivariate analysis of the pilot cohort $(n=72)$ for predicting BR, including $\mathrm{pT}$ and $\mathrm{pN}$ status, age, Gleason score, and total serum PSA concentration, TSR did not show a prognostic relevance (Cox regression model, Supplementary Figure S2).

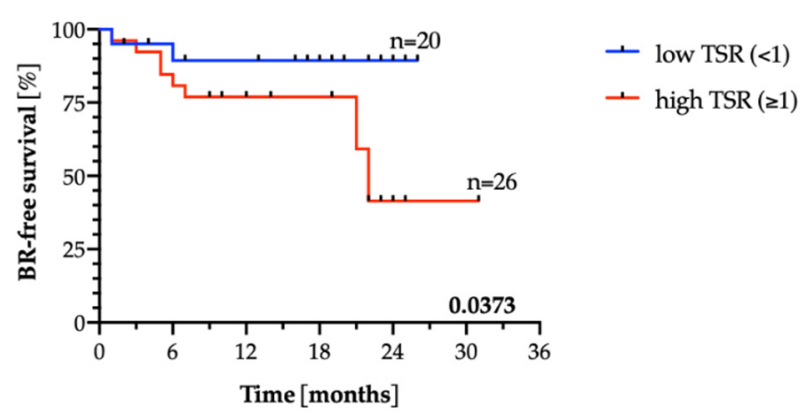

Figure 3. Kaplan-Meier estimates of time to biochemical recurrence (BR) in the pilot cohort $(n=72)$. Note that not all patients are included in Kaplan-Meier analysis as the exact timepoints of BR occurrence for some patients were missing.

\subsection{Clinical Significance of TSR in the Validation Cohort}

TSR status did not correlate to any clinico-pathological parameter including age, pT status, pN status, Gleason Grading score, and preoperative PSA in the validation cohort (Supplementary Table S2). High TSR appeared to indicate a shorter time to biochemical recurrence in the validation cohort of PCa patients (Log-rank test, $n=209, p=0.0072$, Figure 4A). In the multivariate analysis, including $\mathrm{pT}$ and $\mathrm{pN}$ status, age, Gleason score, total serum PSA concentration, and TSR (Cox regression model), TSR predicted BR independent of other factors, i.e., pT, $\mathrm{pN}$, and age ( $p=0.04$, HR 2.75, 95\%CI 1.07-7.03; Figure 4B). Additionally, when the validation cohort was only limited to d'Amico high risk patients, high TSR still appeared to indicate a shorter time to biochemical recurrence (Log-rank test, $n=158, p=0.0149$, Supplementary Figure S3).

\subsection{RNA Expression Characteristics in Relation to the TSR Score}

In order to investigate the gene expression differences between tumors with low and high TSR, we applied multigene expression analysis (using nCounter ${ }^{\circledR}$ PanCancer Progression Panel, NanoString) of 42 tissue cores, among which 21 (50\%) were classified as low and $21(50 \%)$ as high TSR. We observed that tumors with a low TSR score showed the upregulation of 14 genes and the downregulation of 2 genes ( $p$-value $\leq 0.05)$, as shown in Supplementary Table S3. The genes upregulated in tumors with low TSR were mostly associated with extracellular matrix organization and regulation (i.e., COL6A1, TGFBR2, PECAM1, MMP2, CTSK) and cell adhesion regulation (i.e., ADAM17). Tumors categorized with low TSR score also showed higher expression of transcription factor, FOXO4, whereas 2 upregulated genes in high TSR samples were encoding hexokinase 2 (HK2, an enzyme involved in glucose metabolism) and Claudin-7 (CLDN7, a protein involved in tight junction formation), as presented in Figure 5. 
(a)

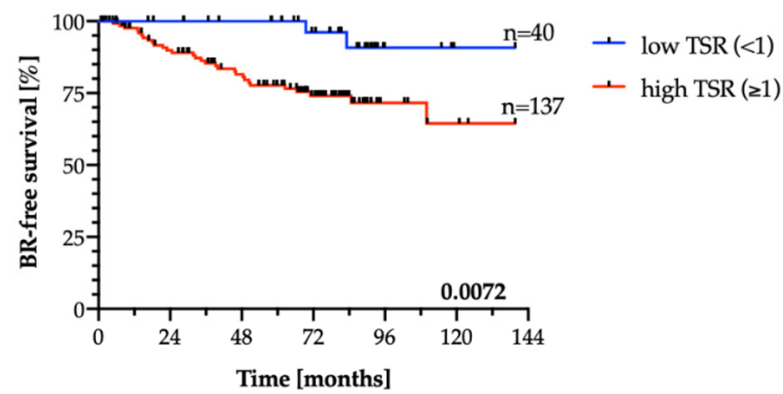

(b)

\begin{tabular}{|ccccccccc|}
\hline Parameter & Group & \multicolumn{3}{c}{ univariate } & \multicolumn{3}{c|}{ multivariate } \\
& & p-value & HR & CI 95\% & p-value & HR & CI 95\% \\
Age & 264 vs. $<64$ & 0.067 & 1.781 & $0.959-3.308$ & - & - & - \\
T status & T3-4 vs. T2a-c & $\mathbf{0 . 0 0 7}$ & $\mathbf{2 . 5 9 2}$ & $\mathbf{1 . 3 0 5 - 5 . 1 4 6}$ & $\mathbf{0 . 0 1 3}$ & $\mathbf{2 . 3 9 7}$ & $\mathbf{1 . 2 0 2 - 4 . 7 8 1}$ \\
N status & N1 vs. N0 & $\mathbf{0 . 0 0 4}$ & $\mathbf{1 . 1 0 3}$ & $\mathbf{1 . 0 3 1 - 1 . 1 8 1}$ & $\mathbf{0 . 0 0 9}$ & $\mathbf{1 . 0 9 6}$ & $\mathbf{1 . 0 2 3 - 1 . 1 7 3}$ \\
Gleason score & $>$ 7 vs. $\leq 7$ & 0.220 & 1.716 & $0.724-4.069$ & - & - & - \\
tPSA & 210 ng $/$ ul vs. $<10$ ng/ul & 0.059 & 1.779 & $0.978-3.237$ & - & - & - \\
TSR & high vs. low & $\mathbf{0 . 0 3 6}$ & $\mathbf{2 . 7 1 0}$ & $\mathbf{1 . 0 6 5 - 6 . 8 9 6}$ & $\mathbf{0 . 0 3 5}$ & $\mathbf{2 . 7 4 8}$ & $\mathbf{1 . 0 7 4 - 7 . 0 3 2}$ \\
\hline
\end{tabular}

Figure 4. Clinical significance of TSR in a validation cohort. (a) Kaplan-Meier estimates of time to biochemical recurrence (BR) in validation cohort, $n=209$. Note that not all patients are included in Kaplan-Meier analysis as the timepoints of BR occurrence for some patients were missing. (b) Uniand multivariate analysis in the whole validation cohort. Statistically significant results are bolded.

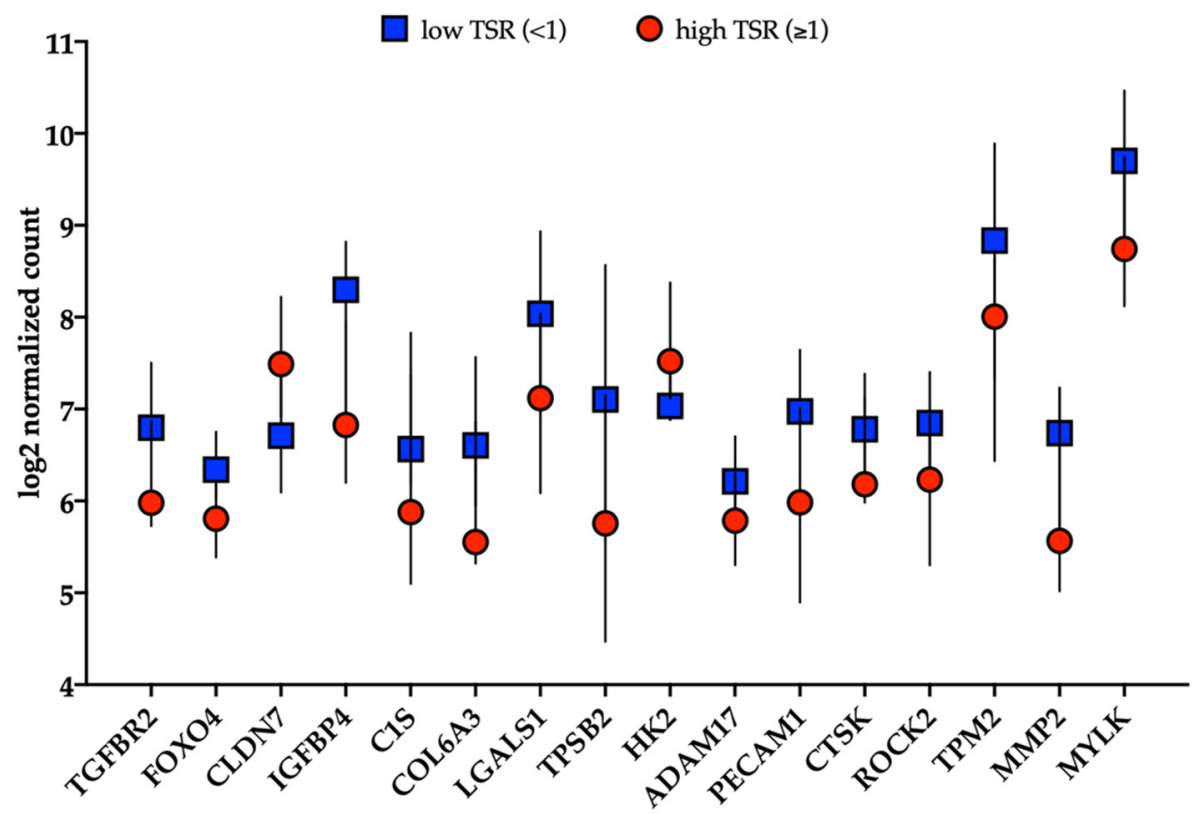

Figure 5. Genes diversly expressed in relation to the TSR score. Statistical significance was considered at $p$-value $\leq 0.05, n=42$.

\section{Discussion}

Tumor-to-stroma ratio is a simple and reliable parameter, which seems to facilitate patient's diagnosis and prognosis in many types of solid tumors [16]. Its evaluation has the potential to be partially or fully automated. Here, we show that automatically assessed TSR can be of clinical significance in PCa patients.

In our study, we divided cohorts into low and high TSR, as in the vast majority of studies, where $50 \%$ threshold was used to categorize patients [10-12,16,17,29,37]. Thus, our evaluation was performed on all informative tumor samples available for each patient, and both versions of selection of minimal or maximal TSR per patient (i.e., the lowest or 
the highest TSR score assigned to a patient) were tested statistically (data not shown). In the presented study, high TSR showed an unfavorable prognosis. It was also shown to be an independent prognostic factor in the multivariate analysis, independent of age, $\mathrm{pT}$, and $\mathrm{pN}$ in the validation cohort. Its lack of prognostic relevance in uni- and multivariate analysis in the pilot cohort can be biased by the low number of cases.

This observation was supported by transcriptomic analysis. Tumors categorized into low and high TSR score showed differential expression of various genes. The genes upregulated in tumors with low TSR score were mostly associated with extracellular matrix and cell adhesion regulation. Interestingly, tumors with low TSR also showed higher expression of a transcription factor FOXO4, which has been reported as a metastasis suppressor [38] in PCa. This suggests that stroma plays a protective role in PCa development. In the future, it could be worth combining the evaluation of TSR with other molecular markers. Such combination of analyzing the TSR and staining for another transcription factor (SMAD4) improved prediction of clinical outcome [39] in colon carcinoma.

Using automated digital images-based evaluation of EpCAM-stained tumor specimens, we correctly analyzed all tumor fragments of the pilot cohort and $91 \%$ of tumor fragments in the validation cohort. Automation may reduce inter-observer variation, improving the compliance and accuracy of the results, as the human eye is not able to distinguish precisely, e.g., the blank spaces caused by gland architecture in prostate tissue [14]. However, it still merits some limited assistance and visual verification. Such inaccuracies were, however, observed in only $4 \%$ of all analyzed tumors; therefore, we decided to assess them visually in order to not bias the clinical results by simple sample exclusion. In our study, tumor cells were stained with anti-EpCAM antibody (brown), which contrasted to EpCAM-negative stroma (blue). This marker-dependent protocol provides a clear and precise detection of tumor cells area in comparison to evaluation based on the standard hematoxylin-eosin staining [9,12,14,17,18,23,24,37,40-43]. Both approaches have some limitations. EpCAM is not an ideal marker to identify tumor area, as it might be downregulated in some tumor cells undergoing epithelial-mesenchymal transition $[44,45]$. Indeed, a few tumor fragments were EpCAM-negative and required additional visual verification. In the future, different markers of tumor cells (e.g., a cocktail of different antibodies) should be used to potentially identify all tumor cells.

The presented data suggest that, although TSR evaluation has not yet been implemented in routine pathologic diagnostics, it has the potential for integration together with the TNM staging system [15]. In PCa, TSR seems to be a simple marker to assess with high prognostic potential. Of note, the partial or even full automation of TSR evaluation is probably attainable in the broad spectrum of solid tumors. Nevertheless, further improvement and validation of the proposed methodology on a larger cohort of patients is still required.

\section{Material and Methods}

The study has been approved by the local Ethics Committee (i.e., Ethik Kommission der Aerztekammer Westfalen-Lippe und der Medizinischen Fakultaet der Westfaelischen Wilhelms-Universitaet Muenster, Germany, no 2007-467-f-S and Independent Bioethics Committee for Scientific Research at Medical University of Gdańsk, no. NKBBN/286/2018).

\subsection{Pilot Study to Test Feasibility of Quantification Method}

In a pilot study, a total of 128 primary tumor samples corresponding to $72 \mathrm{~d}^{\prime}$ Amico high risk PCa patients, who underwent radical prostatectomy (RP) at the Department of Urology at the Medical University of Gdańsk (Poland) in years 2018-2020, were analyzed (Table 1). Tumor specimens were prepared as tumor microarrays (TMAs) that consisted of 3 tumor fragments per patient, including fragments of tumoral invasive front, and tumor with highest and dominant Gleason score. For further analysis, only tumor fragments containing fragments with the highest and dominant Gleason were included. 
Table 1. Distribution of clinical parameters in the pilot and validation cohort of eligible patients. PSA, prostate-specific antigen. Note that not all numbers sum up to 72 and 209 due to the missing data.

\begin{tabular}{|c|c|c|c|c|c|}
\hline \multirow{2}{*}{$\begin{array}{c}\text { Clinical and Pathological } \\
\text { Parameters }\end{array}$} & \multicolumn{3}{|c|}{ Pilot Cohort } & \multicolumn{2}{|c|}{ Validation Cohort } \\
\hline & Status & $n$ & $\%$ & $n$ & $\%$ \\
\hline \multirow[t]{3}{*}{ Age (years) } & $<$ median (65) & 37 & 52.1 & 102 & 48.8 \\
\hline & $\geq$ median (65) & 34 & 47.9 & 107 & 51.2 \\
\hline & Total & 72 & & 209 & \\
\hline \multirow[t]{4}{*}{ T status } & pT2 & 34 & 52.2 & 95 & 45.4 \\
\hline & pT3 & 31 & 47.5 & 94 & 45.0 \\
\hline & pT4 & 0 & 0.0 & 20 & 9.6 \\
\hline & Total & 65 & & 209 & \\
\hline \multirow[t]{3}{*}{$\mathrm{N}$ status } & pN0 & 62 & 93.9 & 191 & 94.1 \\
\hline & pN1-2 & 4 & 6.1 & 12 & 5.9 \\
\hline & Total & 66 & & 203 & \\
\hline \multirow[t]{4}{*}{ Gleason score sum } & $<7$ & 0 & 0.00 & 52 & 24.9 \\
\hline & 7 & 45 & 64.3 & 140 & 67.0 \\
\hline & $>7$ & 25 & 35.7 & 17 & 8.1 \\
\hline & Total & 70 & & 209 & \\
\hline \multirow[t]{3}{*}{ Preoperative PSA } & $<10 \mathrm{ng} / \mathrm{ml}$ & 46 & 63.9 & 132 & 65.5 \\
\hline & $\geq 10 \mathrm{ng} / \mathrm{ml}$ & 26 & 36.1 & 76 & 36.5 \\
\hline & Total & 72 & & 205 & \\
\hline \multirow[t]{4}{*}{$\mathrm{d}^{\prime}$ Amico scale } & low risk & 0 & 0.0 & 2 & 1.0 \\
\hline & intermediate risk & 0 & 0.0 & 46 & 22.3 \\
\hline & high/very high risk & 72 & 100.0 & 158 & 76.7 \\
\hline & Total & 72 & & 206 & \\
\hline \multirow[t]{3}{*}{ Biochemical recurrence } & No & 34 & 70.8 & 166 & 79.4 \\
\hline & Yes & 14 & 29.2 & 43 & 20.6 \\
\hline & Total & 48 & & 209 & \\
\hline
\end{tabular}

\subsection{Patient Characteristics of Validation Cohort}

A total of 800 tumor fragments were collected from 400 PCa patients undergoing RP at the Department of Urology at the University Clinic Münster (Germany) in the years 2002-2004. Tumor specimens were prepared as TMAs as described [46,47], wherein two fragments of a tumor with the highest Gleason score (GS) were collected from each patient. Samples were obtained from 2 tumor foci (multifocal PCa) or 2 different areas of a tumor (monofocal PCa). The last follow-up was performed in September 2019 (resulting in up to 17 years follow-up). Biochemical recurrence was defined if PSA level increased above $0.1 \mathrm{ng} / \mathrm{mL}$ after RP in two consecutive assessments. Time to biochemical recurrence was defined as time between RP and the first timepoint of PSA above $0.1 \mathrm{ng} / \mathrm{mL}$. Patients were classified using the d'Amico classification as previously reported $[48,49]$. Patients that received neoadjuvant androgen deprivation therapy were excluded from the study $(n=27)$. Patients enrolled in this study were characterized by variable clinico-pathological parameters (Table 1).

\subsection{Immunohistochemistry for EpCAM and Different Markers Associated with Tumor Cells}

Tumor samples were stained immunohistochemically for epithelial cell adhesion molecule (EpCAM) in order to visualize tumor cells [50]. Briefly, tissue microarrays (TMAs) were stained with the use of anti-EpCAM, NCL-ESA Novocastra antibody (diluted 1:75), envisioned with EnVision Kit Rabbit/Mouse (Dako), and counterstained with hematoxylin. In this system, 3,3'-Diaminobenzidine (DAB) is oxidized to brown precipitate by hydrogen peroxide in a reaction catalyzed by horseradish peroxidase. Different tumor cell markers (including different keratins, E-cadherin, N-cadherin, vimentin, Ki-67, ALDH1, and others) 
were also stained by immunohistochemistry, evaluated, and categorized as negative or positive as described [46,47,50-54].

\subsection{Evaluation of TSR}

In the pilot cohort, photomicrographs of tumor fragments were acquired using the Pannoramic 250 II Flash (3D Histech, Hungary) equipped with the $20 \times$ objective. Photomicrographs of each tumor sample in the validation cohort were acquired with the transmitted light microscope Olympus BX63 Olympus (Japan) equipped with 10x objective (UPlanSApo, NA 0.4) and a 36-bit color camera DFC450C (Leica, Germany). Automated evaluation of TSR in each examined tumor sample was carried out using custom-built Jython Fiji plugin [55]. The plugin performed a color deconvolution from the RGB image to H-DAB staining using the Fiji Plugin Color Deconvolution [56]. The tumor area was recognized as the (DAB) channel of the $\mathrm{H}-\mathrm{DAB}$ deconvoluted image using the Moment's Threshold method, after median filtering. The stroma area was recognized using the hematoxylin channel of the H-DAB deconvoluted image using the Otsu's Threshold method, after median filtering. The plugin considered valid stroma regions only the ones not overlapping with the tumor region. Then, TSR ratio was evaluated as the ratio between the area of the tumor cells and the area of the stroma. In this study, all tumor fragments were analyzed automatically and verified visually. Tumor specimens technically invalid or without tumor cells, as well as specimens without tumor cells in four sides of the field of view (north, south, east, west), according to van Pelt et al.'s recommendations [16,17], were excluded. Visual analysis of TSR was applied for EpCAM-negative tumors $(n=19)$. TSR evaluation was assessed for two tumor fragments (i.e., TMA tissue cores) per patient. Minimal and maximal value was counted for each patient (if two tissue cores were valid) in order to test their potential clinical significance. If one tumor fragment was excluded, only the remaining one was assigned to a patient. Various cut-offs (e.g., mean, median, and quartiles) were used to categorize TSR and examine its significance in PCa.

\subsection{RNA Extraction}

Total mRNA was extracted from 42 samples prepared as formalin-fixed paraffinembedded (FFPE) primary prostate tumor tissue cores (three $20 \mu \mathrm{m}$-thick, unstained FFPE sections per patient) using the RNeasy Mini Kit (Qiagen, Hilden, Germany) according to the manufacturer's protocol. RNA integrity was assessed using the Agilent 2100 Bioanalyzer (Agilent Technologies, Santa Clara, CA, USA) with the Agilent RNA 6000 Pico Kit (Agilent Technologies).

\section{6. nCounter Gene Expression Assay}

Extracted RNA ( $4 \mu \mathrm{L})$ was pre-amplified using the nCounter Low RNA Input Kit (NanoString Technologies, Seattle, WA, USA) with the dedicated Primer Pool covering the sequences of 730 immune-related genes included in the nCounter Cancer Progression Profiling Panel (NanoString Technologies). Pre-amplified samples were analyzed using the NanoString nCounter Analysis System (NanoString Technologies) according to the manufacturer's procedures for hybridization, detection, and scanning. The collected RNA expression results were then correlated to the TSR score of the corresponding tissue core.

\subsection{Statistical Analysis}

The cut-off with the best clinical relevance was selected and presented in this study; for each patient, the maximal value obtained from informative and eligible tumor samples was categorized as low TSR (TSR score $<1$ ), or high TSR (TSR score $\geq 1$ ). Statistical analysis was performed using IBM SPSS software Statistics 25.0.0.2 licensed for the University of Gdańsk. Graphs were prepared using the GraphPad Prism software (8.0d licensed for the Medical University of Gdańsk). The comparison of TSR and clinical data was performed using the Chi-squared or Fisher's exact tests. Survival analyses were performed using the Log-rank (Mantel Cox) test and visualized by Kaplan-Meier plots. Uni- and multivariate analysis 
was assessed using the Cox Regression model. The results were considered statistically significant at $p<0.05$.

\section{Conclusions}

To conclude, this study indicated that automatically quantified TSR may support identification of patients at the higher risk of PCa recurrence. Thus, this methodology carries potential to further develop and improve pathological expertise and routine diagnostics in $\mathrm{PCa}$, and plausibly also other solid tumors.

Supplementary Materials: The following are available online at https://www.mdpi.com/article/10 $.3390 / \mathrm{jpm} 11111088 / \mathrm{s} 1$, Figure S1: Comparison of visual and automated TSR evaluation in relation to EpCAM staining intensity, Figure S2: Uni- and multivariate analysis in the whole pilot cohort $(n=72)$. Figure S3: Kaplan-Meier estimates of time to biochemical recurrence (BR) in d'Amico high risk patients from validation cohort $(n=158)$, Table S1: title Comparison of TSR status to the clinic-pathological parameters in the pilot cohort, Table S2 Comparison of TSR status to the clinic-pathological parameters in the validation cohort, Table S3 RNA expression data in tissue cores classified as low and high TSR.

Author Contributions: N.B.-K. had full access to all the data in the study and takes responsibility for the integrity of the data and the accuracy of the data analysis. Conception and design: N.B.-K.; Acquisition of data: J.S. (Julia Smentoch), P.N., M.P., E.E., A.S. and M.N.; Analysis and interpretation of data: J.S. (Julia Smentoch), P.N., E.M., N.B.-K.; Drafting of the manuscript: J.S. (Julia Smentoch), P.N. and N.B.-K.; Critical revision of the manuscript for the important intellectual content: P.N., M.P., A.S., N.B.-K.; Statistical analysis: J.S. (Julia Smentoch), P.N., M.P. and N.B.-K.; Obtaining funding: N.B.-K.; Administrative, technical, or material support: P.M., B.B., A.J.Ż., E.E., A.S., M.S., M.M., J.S. (Jolanta Szade), L.K. and J.S. (Julia Smentoch). Supervision: N.B.-K. All authors have read and agreed to the published version of the manuscript.

Funding: This research was funded by the National Science Centre (grant number: DEC-2017/01/X/NZ4/02120 and 2017/26/D/NZ5/01088 for N.B.-K.). This work was supported by fellowships from the Italian Association for Cancer Research number 19416 (P.N.) and Fondazione Umberto Veronesi Post-doctoral fellowship (P.N.). For digitalization of the photomicrographs of the pilot cohort Digitalization Platform of Imaging Data of BBMRI.pl was used (grant number: DIR/WK/2017/01 Ministry of Education and Sciences Poland).

Institutional Review Board Statement: The study was conducted according to the guidelines of the Declaration of Helsinki, and approved by the local Ethics Committee (i.e., Ethik Kommission der Aerztekammer Westfalen-Lippe und der Medizinischen Fakultaet der Westfaelischen WilhelmsUniversitaet Muenster, Germany, no 2007-467-f-S and Independent Bioethics Committee for Scientific Research at Medical University of Gdańsk, no. NKBBN/286/2018).

Informed Consent Statement: Informed consent was obtained from all subjects involved in the study. Written informed consent has been obtained from the patients to publish this paper.

Data Availability Statement: The data presented in this study are available on request from the corresponding author.

Acknowledgments: The authors acknowledge Kamila Kreft for excellent technical assistance in the Biobanking and Biomolecular Resources Research Infrastructure (BBMRI.pl), Gdansk, Poland.

Conflicts of Interest: The authors declare no conflict of interest.

\section{References}

1. Culp, M.B.; Soerjomataram, I.; Efstathiou, J.A.; Bray, F.; Jemal, A. Recent Global Patterns in Prostate Cancer Incidence and Mortality Rates. Eur. Urol. 2019, 77, 38-52. [CrossRef]

2. Bray, F.; Ferlay, J.; Soerjomataram, I.; Siegel, R.L.; Torre, L.A.; Jemal, A. Global cancer statistics 2018: GLOBOCAN estimates of incidence and mortality worldwide for 36 cancers in 185 countries. CA Cancer J. Clin. 2018, 68, 394-424. [CrossRef] [PubMed]

3. Ferrer-Batallé, M.; Llop, E.; Ramírez, M.; Aleixandre, R.N.; Saez, M.; Comet, J.; de Llorens, R.; Peracaula, R. Comparative study of blood-based biomarkers, $\alpha 2,3$-sialic acid PSA and PHI, for high-risk prostate cancer detection. Int. J. Mol. Sci. 2017, 18, 845. [CrossRef] [PubMed] 
4. Tyekucheva, S.; Bowden, M.; Bango, C.; Giunchi, F.; Huang, Y.; Zhou, C.H.; Bondi, A.; Lis, R.; Van Hemelrijck, M.; Andrén, O.; et al. Stromal and epithelial transcriptional map of initiation progression and metastatic potential of human prostate cancer. Nat. Commun. 2017, 8, 420. [CrossRef]

5. Taylor, R.; Risbridger, G. Prostatic Tumor Stroma: A Key Player in Cancer Progression. Curr. Cancer Drug Targets 2008, 8, 490-497. [CrossRef] [PubMed]

6. Chung, L.W.K.; Baseman, A.; Assikis, V.; Zhau, H.E. Molecular insights into prostate cancer progression: The missing link of tumor microenvironment. J. Urol. 2005, 173, 10-20. [CrossRef] [PubMed]

7. Valkenburg, K.C.; de Groot, A.E.; Pienta, K.J. Targeting the tumour stroma to improve cancer therapy. Nat. Rev. Clin. Oncol. 2018, 15, 366-381. [CrossRef]

8. Levesque, C.h.; Nelson, P.S. Cellular Constituents of the Prostate Stroma: Key Contributors to Prostate Cancer Progression and Therapy Resistance. Cold Spring Harb. Perspect. Med. 2019, 8, a030510. [CrossRef] [PubMed]

9. Kemi, N.; Eskuri, M.; Herva, A.; Leppänen, J.; Huhta, H.; Helminen, O.; Saarnio, J.; Karttunen, T.J.; Kauppila, J.H. Tumour-stroma ratio and prognosis in gastric adenocarcinoma. Br. J. Cancer 2018, 119, 435-439. [CrossRef]

10. Kemi, N.; Eskuri, M.; Kauppila, J.H. Tumour-stroma ratio and 5-year mortality in gastric adenocarcinoma: A systematic review and meta-analysis. Sci. Rep. 2019, 9, 16018. [CrossRef]

11. Smit, M.; van Pelt, G.; Roodvoets, A.; Meershoek-Klein Kranenbarg, E.; Putter, H.; Tollenaar, R.; van Krieken, J.H.; Mesker, W. Uniform Noting for International Application of the Tumor-Stroma Ratio as an Easy Diagnostic Tool: Protocol for a Multicenter Prospective Cohort Study. JMIR Res. Protoc. 2019, 8, 1-8. [CrossRef] [PubMed]

12. Aurello, P.; Berardi, G.; Giulitti, D.; Palumbo, A.; Tierno, S.M.; Nigri, G.; D'Angelo, F.; Pilozzi, E.; Ramacciato, G. Tumor-Stroma Ratio is an independent predictor for overall survival and disease free survival in gastric cancer patients. Surgeon 2017, 15, 329-335. [CrossRef] [PubMed]

13. Ersvær, E.; Hveem, T.S.; Vlatkovic, L.; Brennhovd, B.; Kleppe, A.; Tobin, K.A.R.; Pradhan, M.; Cyll, K.; Wæhre, H.; Kerr, D.J.; et al. Prognostic value of DNA ploidy and automated assessment of stroma fraction in prostate cancer. Int. J. Cancer 2020, 147, 1228-1234. [CrossRef]

14. Geessink, O.G.F.; Baidoshvili, A.; Klaase, J.M.; Bejnordi, B.E.; Litjens, G.J.S.; van Pelt, G.W.; Mesker, W.E.; Nagtegaal, I.D.; Ciompi, F.; van der Laak, J.A.W.M. Computer aided quantification of intratumoral stroma yields an independent prognosticator in rectal cancer. Cell Oncol. 2019, 42, 331-341. [CrossRef] [PubMed]

15. van Pelt, G.W.; Sandberg, T.P.; Morreau, H.; Gelderblom, H.; van Krieken, J.H.J.M.; Tollenaar, R.A.E.M.; Mesker, W.E. The tumour-stroma ratio in colon cancer: The biological role and its prognostic impact. Histopathology 2018, 73, 197-206. [CrossRef] [PubMed]

16. van Pelt, G.W.; Kjær-Frifeldt, S.; van Krieken, J.H.J.M.; Al Dieri, R.; Morreau, H.; Tollenaar, R.A.E.M.; Sørensen, F.B.; Mesker, W.E. Scoring the tumor-stroma ratio in colon cancer: Procedure and recommendations. Virchows Arch. 2018, 473, 405-412. [CrossRef] [PubMed]

17. Huijbers, A.; Tollenaar, R.A.E.M.; Pelt, G.W.V.; Zeestraten, E.C.M.; Dutton, S.; McConkey, C.C.; Domingo, E.; Smit, V.T.H.B.M.; Midgley, R.; Warren, B.F.; et al. The proportion of tumor-stroma as a strong prognosticator for stage II and III colon cancer patients: Validation in the VICTOR trial. Ann. Oncol. 2013, 24, 179-185. [CrossRef] [PubMed]

18. Zhang, T.; Xu, J.; Shen, H.; Dong, W.; Ni, Y.; Du, J. Tumor-stroma ratio is an independent predictor for survival in NSCLC. Int. J. Clin. Exp. Pathol. 2015, 8, 11348-11355.

19. Chen, Y.; Zhang, L.; Liu, W.; Liu, X. Prognostic Significance of the Tumor-Stroma Ratio in Epithelial Ovarian Cancer. BioMed Res. Int. 2015, 2015, 589301. [CrossRef]

20. Liu, J.; Liu, J.; Li, J.; Chen, Y.; Guan, X.; Wu, X.; Hao, C.h.; Sun, Y.; Wang, Y.; Wang, X. Tumor-stroma ratio is an independent predictor for survival in early cervical carcinoma. Gynecol. Oncol. 2014, 132, 81-86. [CrossRef]

21. Vangangelt, K.M.H.; Tollenaar, L.S.A.; van Pelt, G.W.; de Kruijf, E.M.; Dekker, T.J.A.; Kuppen, P.J.K.; Tollenaar, R.A.E.M.; Mesker, W.E. The prognostic value of tumor-stroma ratio in tumor-positive axillary lymph nodes of breast cancer patients. Int. J. Cancer 2018, 143, 3194-3200. [CrossRef] [PubMed]

22. de Kruijf, E.M.; van Nes, J.G.H.; van de Velde, C.J.H.; Putter, H.; Smit, V.T.H.B.M.; Liefers, G.J.; Kuppen, P.J.K.; Tollenaar, R.A.E.M. Mesker WE. Tumor-stroma ratio in the primary tumor is a prognostic factor in early breast cancer patients, especially in triple-negative carcinoma patients. Breast Cancer Res. Treat. 2011, 125, 687-696. [CrossRef] [PubMed]

23. Roeke, T.; Sobral-Leite, M.; Dekker, T.J.A.; Wesseling, J.; Smit, V.T.H.B.M.; Tollenaar, R.A.E.M.; Schmidt, M.K.; Mesker, W.E. The prognostic value of the tumour-stroma ratio in primary operable invasive cancer of the breast: A validation study. Breast Cancer Res. Treat. 2017, 166, 435-445. [CrossRef]

24. Downey, C.L.; Simpkins, S.A.; White, J.; Holliday, D.L.; Jones, J.L.; Jordan, L.B.; Kulka, J.; Pollock, S.; Rajan, S.S.; Thygesen, H.H.; et al. The prognostic significance of tumour-stroma ratio in oestrogen receptor-positive breast cancer. BJC 2014, 110, 1744-1747. [CrossRef] [PubMed]

25. Panayiotou, H.; Orsi, N.M.; Thygesen, H.H.; Wright, A.I.; Winder, M.; Hutson, R.; Cummings, M. The prognostic significance of tumour-stroma ratio in endometrial carcinoma. BMC Cancer 2015, 15, 955. [CrossRef] [PubMed]

26. Ayala, G.; Tuxhorn, J.A.; Wheeler, T.M.; Frolov, A.; Scardino, P.T.; Ohori, M.; Wheeler, M.; Spitler, J.; Rowley, D.R. Reactive Stroma as a Predictor of Biochemical-Free Recurrence in Prostate Cancer. Clin. Cancer Res. 2003, 9, 4792-4801. [PubMed] 
27. Yanagisawa, N.; Li, R.; Rowley, D.; Liu, H.; Kadmon, D.; Miles, B.J.; Wheeler, T.M.; Ayala, G.E. Reprint of: Stromogenic prostatic carcinoma pattern (carcinomas with reactive stromal grade 3) in needle biopsies predicts biochemical recurrence-free survival in patients after radical prostatectomy. Hum. Pathol. 2008, 39, 282-291. [CrossRef] [PubMed]

28. Bianconi, F.; Álvarez-Larrán, A.; Fernández, A. Discrimination between tumour epithelium and stroma via perception-based features. Neurocomputing 2015, 154, 119-126. [CrossRef]

29. Eminaga, O.; Al-Hamad, O.; Boegemann, M.; Breil, B.; Semjonow, A. Combination possibility and deep learning model as clinical decision-aided approach for prostate cancer. Health Inform. J. 2020, 26, 945-962. [CrossRef]

30. Niazi, M.K.K.; Parwani, A.V.; Gurcan, M.N. Digital pathology and artificial intelligence. Lancet Oncol. 2019, $20,253-261$. [CrossRef]

31. van Pelt, G.; Tollenaar, R.; Mesker, W. Filling the Gap between Microscopic and Automated Analysis of the Tumor-Stroma Ratio. Ann. Colorectal. Res. 2020, 8, 29-32.

32. Du, Y.; Zhang, R.; Zargari, A.; Thai, T.C.; Gunderson, C.C.; Moxley, K.M.; Liu, H.; Zheng, B.; Qiu, Y. Classification of Tumor Epithelium and Stroma by Exploiting Image Features Learned by Deep Convolutional Neural Networks. Ann. Biomed. Eng. 2018, 46, 1988-1999. [CrossRef]

33. Bhargava, H.K.; Leo, P.; Elliott, R.; Janowczyk, A.; Whitney, J.; Gupta, S.; Fu, P.; Yamoah, K.; Khani, F.; Robinson, B.D.; et al. Computationally derived image signature of stromal morphology is prognostic of prostate cancer recurrence following prostatectomy in African American patients. Clin. Cancer Res. 2020, 26, 1915-1923. [CrossRef] [PubMed]

34. $\mathrm{Hu}, \mathrm{Y}$;; Wu, Q.; Gao, J.; Zhang, Y.; Wang, Y. A meta-analysis and The Cancer Genome Atlas data of prostate cancer risk and prognosis using epithelial cell adhesion molecule (EpCAM) expression. BMC Urol. 2019, 19, 67. [CrossRef] [PubMed]

35. Massoner, P.; Thomm, T.; Mack, B.; Untergasser, G.; Martowicz, A.; Bobowski, K.; Klocker, H.; Gires, O.; Puhr, M. EpCAM is overexpressed in local and metastatic prostate cancer, suppressed by chemotherapy and modulated by MET-associated miRNA-200c/205. Br. J. Cancer 2014, 111, 955-964. [CrossRef]

36. Ni, J.; Cozzi, P.J.; Duan, W.; Shigdar, S.; Graham, P.H.; John, K.H.; Li, Y. Role of the EpCAM (CD326) in prostate cancer metastasis and progression. Cancer Metastasis Rev. 2012, 31, 779-791. [CrossRef]

37. Vangangelt, K.M.H.; Green, A.R.; Heemskerk, I.M.F.; Cohen, D.; van Pelt, G.W.; Sobral-Leite, M.; Schmidt, M.K.; Putter, H.; Rakha, E.A.; Tollenaar, R.A.E.M.; et al. The prognostic value of the tumor-stroma ratio is most discriminative in patients with grade III or triple-negative breast cancer. Int. J. Cancer 2020, 146, 2296-2304. [CrossRef]

38. Su, B.; Gao, L.; Baranowski, C.; Gillard, B.; Wang, J.; Ransom, R.; Ko, H.K.; Gelman, I.H. A genome-wide RNAi screen identifies FOXO4 as a metastasis-suppressor through counteracting PI3K/AKT signal pathway in prostate cancer. PLoS ONE 2014, 9, e101411. [CrossRef] [PubMed]

39. Mesker, W.E.; Liefers, G.J.; Junggeburt, J.M.; van Pelt, G.W.; Alberici, P.; Kuppen, P.J.; Miranda, N.F.; van Leeuwen, K.A.; Morreau, H.; Szuhai, K.; et al. Presence of a high amount of stroma and downregulation of SMAD4 predict for worse survival for stage I-II colon cancer patients. Cell Oncol. 2009, 31, 169-178. [PubMed]

40. Scheer, R.; Baidoshvili, A.; Zoidze, S.; Elferink, M.A.G.; Berkel, A.E.M.; Klaase, J.M.; van Diest, P.J. Tumor-stroma ratio as prognostic factor for survival in rectal adenocarcinoma: A retrospective cohort study. World J. Gastrointest. Oncol. 2017, 9, 466-474. [CrossRef]

41. Xi, K.-X.; Wen, Y.-S.; Zhu, C.-M.; Yu, X.-Y.; Qin, R.-Q.; Zhang, X.-W.; Lin, Y.-B.; Rong, T.-H.; Wang, W.-D.; Chen, Y.-Q.; et al. Tumor-stroma ratio (TSR) in non-small cell lung cancer (NSCLC) patients after lung resection is a prognostic factor for survival. J. Thorac. Dis. 2017, 9, 4017-4026. [CrossRef] [PubMed]

42. Eriksen, A.C.; Andersen, J.B.; Lindebjerg, J.; dePont Christensen, R.; Hansen, T.F.; Kjær-Frifeldt, S.; Sørensen, F.B. Does heterogeneity matter in the estimation of tumour budding and tumour stroma ratio in colon cancer? Diagn. Pathol. 2018, 13, 20. [CrossRef] [PubMed]

43. Hansen, T.F.; Kjær-Frifeldt, S.; Lindebjerg, J.; Rafaelsen, S.R.; Jensen, L.H.; Jakobsen, A.; Sørensen, F.B. Tumor-stroma ratio predicts recurrence in patients with colon cancer treated with neoadjuvant chemotherapy. Acta Oncol. 2018, 57, 528-533. [CrossRef] [PubMed]

44. Stylianou, N.; Lehman, M.L.; Wang, C.; Fard, A.T.; Rockstroh, A.; Fazli, L.; Jovanovic, L.; Ward, M.; Sadowski, M.C.; Kashyap, A.S.; et al. A molecular portrait of epithelial-mesenchymal plasticity in prostate cancer associated with clinical outcome. Oncogene 2019, 38, 913-934. [CrossRef] [PubMed]

45. Königsberg, R.; Obermayr, E.; Bises, G.; Pfeiler, G.; Gneist, M.; Wrba, F.; de Santis, M.; Zeillinger, R.; Hudec, M.; Dittrich, C. Detection of EpCAM positive and negative circulating tumor cells in metastatic breast cancer patients. Acta Oncol. 2011, 50, 700-710. [CrossRef]

46. Nastały, P.; Filipska, M.; Morrissey, C.; Elke, E.; Semjonow, A.; Brandt, B.; Pantel, K.; Bednarz-Knoll, N. ALDH1-Positive Intratumoral Stromal Cells Indicate Differentiated Epithelial-Like Phenotype and Good Prognosis in Prostate Cancer. Transl. Res. 2019, 203, 49-56. [CrossRef] [PubMed]

47. Omari, A.; Nastały, P.; Stoupiec, S.; Omari, A.; Nastały, P.; Stoupiec, S.; Bałabas, A.; Dąbrowska, M.; Bielińska, B.; Huss, S. Somatic Aberrations of BRCA1 Gene are Associated with ALDH1, EGFR, and Tumor Progression in Prostate Cancer. Int. J. Cancer 2019, 144, 607-614. [CrossRef] [PubMed] 
48. D'Amico, A.V.; Whittington, R.; Malkowicz, S.B.; Schultz, D.; Blank, K.; Broderick, G.A.; Tomaszewski, J.E.; Renshaw, A.A.; Kaplan, I.; Beard, C.J.; et al. Biochemical outcome after radical prostatectomy, external beam radiation therapy, or interstitial radiation therapy for clinically localized prostate cancer. JAMA 1998, 280, 969-974. [CrossRef] [PubMed]

49. Mohler, J.; Bahnson, R.R.; Boston, B.; Busby, J.E.; D’Amico, A.; Eastham, J.A.; Enke, C.A.; George, D.; Horwitz, E.M.; Huben, R.P.; et al. NCCN clinical practice guidelines in oncology: Prostate cancer. J. Natl. Compr. Canc. Netw.. 2010, 8, 162-200. [CrossRef]

50. Smentoch, J.; Szade, J.; Żaczek, A.J.; Eltze, E.; Semjonow, A.; Brandt, B.; Bednarz-Knoll, N. Low numbers of vascular vessels correlate to progression in Hormone-Naïve prostate carcinomas undergoing radical prostatectomy. Cancers 2019, $11,1356$. [CrossRef] [PubMed]

51. Bednarz, N.; Eltze, E.; Semjonow, A.; Rink, M.; Andreas, A.; Mulder, L.; Hannemann, J.; Fisch, M.; Pantel, K.; Weier, H. BRCA1 Loss Preexisting in Small Subpopulations of Prostate Cancer is Associated with Advanced Disease and Metastatic Spread to Lymph Nodes and Peripheral Blood. Clin. Cancer Res. 2010, 16, 3340-3348. [CrossRef] [PubMed]

52. Heßling, S. Prognostische Relevanz in Bezug auf die Expression von LOXL2 bei den Verschiedenen Manifestationsformen des Prostatakarzinoms (Prognostic Relevance with Respect to the Expression of LOXL2 in the Different Manifestations of Prostate Cancer). Ph.D. Thesis, University of Münster, Münster, Germany, 2007.

53. Schmidt, H.; Semjonow, A.; Csiszar, K.; Korsching, E.; Brandt, B.; Eltze, E. Mapping Eines Deletionsintervalls auf 8p21-22 beim Prostatakarzionom mittels Gendosis-PCR (Mapping of a Deletion Interval on 8p21-22 in the Prostate Carcinoma Using Gene-Dose PCR). Verh. Dtsch. Ges. Pathol. 2007, 91, 302-307. [PubMed]

54. Nastały, P.; Stoupiec, S.; Popęda, M.; Smentoch, J.; Schlomm, T.; Morrissey, C.; Żaczek, A.J.; Beyer, B.; Tennstedt, P.; Graefen, M.; et al. EGFR as a stable marker of prostate cancer dissemination to bones. Br. J. Cancer 2020, 123, 1767-1774. [CrossRef] [PubMed]

55. Schindelin, J.; Arganda-Carreras, I.; Frise, E.; Kaynig, V.; Longair, M.; Pietzsch, T.; Preibisch, S.; Rueden, C.; Saalfeld, S.; Schmid, B.; et al. Fiji: An open-source platform for biological-image analysis. Nat. Methods 2012, 9, 676-682. [CrossRef] [PubMed]

56. Ruifrok, A.C.; Johnston, D.A. Quantification of histochemical staining by color deconvolution. Anal. Quant. Cytol. Histol. 2001, 23, 291-299. [PubMed] 